Original Research Paper

\title{
Social Distancing; Meaning, Adoption, Barriers and Social Implications as a Coronavirus Spread Mitigation Strategy in Kenya
}

\author{
Keith Kiswili Julius \\ Department of Social Sciences, Chuka University, P.O Box 109-60400, Chuka, Kenya
}

Article history

Received: $12-08-2020$

Revised: 20-02-2021

Accepted: 23-02-2021

Email: kkiswili@chuka.ac.ke

\begin{abstract}
As the Covid-19 pandemic continues to spread across the globe, several strategies have been promoted for mitigating the spread of the virus. Since social distancing remains one of the most efficacious strategies for slowing the spread of the virus, the Kenyan government has issued stringent measures around it. This study sought to; establish the meaning of social distancing among Kenyans; investigate its rate of adoption as a mitigation strategy; to establish the potential barriers to its adoption and to document the social implications of the practice. The study employed a descriptive design. Primary data was collected using a semi-structured questionnaire that was administered to 265 respondents drawn conveniently from different Email and WhatsApp databases. Secondary data on Covid-19 was collected from different sources. Quantitative data was input into SPSS and descriptive and statistics drawn. Qualitative data was coded and analyzed using Nnivo for content and thematic analysis. The study established that the majority of Kenyans have a good understanding of social distancing as coronavirus mitigation strategy as per the WHO guidelines; a great majority were observing it; there were certain barriers to its successful implementation and that there were social implications for observing it.
\end{abstract}

Keywords: Coronavirus, Social Distancing, Mitigation Strategy

\section{Introduction}

Covid-19 has hit the globe with devastating consequences. Coronaviruses are a large family of viruses that usually cause mild to moderate upper-respiratory tract illnesses, like the common cold. However, even though coronaviruses are endemic in animals, three new strains of the virus have emerged from animal reservoirs over the past two decades to cause serious and widespread illness and death among humans (NIH, 2020). Among the most remarkable outbreaks caused by this virus among a human population was a Severe Acute Respiratory Syndrome (SARS) caused by SARS-CoV which erupted in Guangdong, China, 2002 (Zhong et al., 2003). A decade later, another pathogenic coronavirus, known as Middle East Respiratory Syndrome Coronavirus (MERS-CoV) caused a pandemic in Middle Eastern countries (Wang et al., 2013).

In 2019, the world was awakened to the reality of another coronavirus outbreak in Wuhan city, Hubei Province, China. This new outbreak referred to as the severe acute respiratory syndrome was caused by a novel coronavirus 2 (SARS-CoV-2; formerly called 2019-nCoV) (WMHC, 2020). As the outbreak spread from Wuhan to other countries across the globe, its name was changed to Covid-19 to avoid stigmatizing the virus's origins in terms of populations, geography, or animal associations (Zhu et al., 2020; WHO, 2020a). Due to its rapid spread across the globe, WHO declared COVID-19 a global pandemic in March 2020 (WHO, 2020b).

Patients infected with COVID-19 fall under three broad categories based on the clinical manifestations they display. The first category is comprised of individuals who have the infection but are largely asymptomatic. The second category is those individuals who exhibit relatively few symptoms (paucisymptomatic) while the third category is made up of individuals with very severe clinical conditions that are characterized by severe respiratory failure that necessitates the use of artificial ventilation and support in an Intensive Care Unit (ICU). Pneumonia is the most frequent serious manifestation of infection, characterized primarily by fever, cough, dyspnea and bilateral infiltrates on chest imaging. 
There are no specific clinical features that can yet reliably distinguish COVID-19 from other viral respiratory infections. Other, less common symptoms have included headaches, sore throat and rhinorrhea. In addition to respiratory symptoms, gastrointestinal symptoms (e.g., nausea and diarrhea) have also been reported and in some patients, they may be the presenting complaint. Respiratory droplet transmission is the main route and it can also be transmitted through person-to-person contacts by asymptomatic carriers (Lupia et al., 2019; Yang et al., 2020).

While tremendous progress has been made in the area of treatments, therapies and vaccines for Covid19 especially among the developed economies, nonpharmacological interventions still remain the potent most measures for stemming the spread of the virus. The CDC has come up with several strategies aimed at slowing the viral transmission such as social distancing, self-quarantine and isolation, washing hands and sanitizing frequently (CDC, 2019). As of 19th February, 2021, Covid-19 had infected $109,594,835$ and killed 2,424,060 people globally (WHO, 2021). It has also significantly altered the prevailing social and economic arrangements.

\section{Problem Statement}

Social distancing has been touted by many health organizations such as the World Health Organization and the Center for Disease Control has one of the most efficacious strategies for containing the spread of the Covid-19. Taking a cue from these organizations, The Kenyan government instituted stringent social distancing regulations in various social environments such as public transport, shopping malls, eateries and joints of entertainment and worship.

Yet despite the institution of these regulations and also its efficacy as a tool for slowing down the rate of new Coronavirus infections, social distancing remains an elusive practice in the African culture. Anecdotal evidence suggests that African culture advocates for communal living whereby several members of the same family live under one roof with little personal space. Also, among the Africans, the cultural norm of being together during family gatherings and social gatherings such as marriages, burials and other cultural ceremonies making it comparatively harder to enforce strict social distance compared to other regions like Europe and the United States. Social distancing, therefore, though a valid containment solution for the novel coronavirus doesn't grasp a reality that is extremely widespread across Africa: People survive difficulty by coming together as communities of care, not pulling apart in a retreat into individualism.

Compounding this problem and, which also makes it difficult to design and implement extensive social distancing measures in African countries, especially the low-income ones, in particular, include large households, overcrowded dwellings, frequent and close contact between the young and elderly, constrained access to clean water, inability to earn a living while staying at home, or lack of liquidity to stock up on food and other supplies, which requires frequent shopping trips. As (Dahab et al., 2020) posits, designing and implementing social distancing measures in these contexts can be difficult, but putting more measures in place is still necessary to save lives.

In view of the above observation, this study therefore sought to explore the following objectives:

i. To find out the meanings Kenyans have developed for social distancing

ii. To establish if Kenyans are indeed exercising social distancing as a mitigation strategy for the spread of the coronavirus

iii. To establish the barriers to effective adoption of social distancing as a strategy for controlling the spread of the Coronavirus

iv. To establish the social implications for the adoption of social distancing as a strategy for controlling the spread of the Coronavirus

Consequently, the study was guided by the following research questions:

i. What does the concept of social distancing mean to Kenyans?

ii. Are Kenyans exercising social distancing as a mitigation strategy for the spread of the coronavirus?

iii. What are the barriers to effective adoption of social distancing as a strategy for controlling the spread of the Coronavirus among Kenyans?

iv. What are the social implications for the adoption of social distancing as a strategy for controlling the spread of the Coronavirus among Kenyans?

This study was motivated by the fact that there is a dearth of literature on the concept of social distancing and more precisely on its usage, limitations and impacts as a preventive strategy for the spread of diseases in Kenya. It was therefore, hoped that the study would elucidate important insights on the phenomenon for decision making.

\section{Literature Review}

The concept of social distance isn't new in sociological literature. Different sociologists have over the years attempted to show the different social situations in which social distance as a sociological concept can be applied. In order to appreciate its usage 
as a medical intervention, it might be worthwhile to look at its usage from a sociological perspective.

Social distance as a sociological concept is somewhat vague because it entails a broad spectrum of social constructions. On one level, it may imply the relations between individuals as members of social groups while on another level it may denote the relationship between individuals as they portray their individuality, behavior, or other social acts towards others. On a third level, it may imply group prejudices and cultural differences and, how these subsequently affect group interactions. In sociological literature, the earliest mention of the concept of social distance can be attributed to (Tarde, 1962), who in his work "The laws of Imitation", inferred that distance exists between classes and it is measured by the degree of imitation between them. Invariably, class differences are class distance.

Simmel (1906), further advanced on the concept noting that the very notion of social distance is not rooted in familiarity of one individual to another but rather on their reciprocal degree of imitating or knowing each other. He argued that around each individual is a sphere made of up of his/her affairs and into this sphere, some people may not intrude at all, some others may intrude partly while other people may intrude entirely. He concluded that "the radius of that sphere, to speak marks the distance" (Simmel, 1908), in "Sociologie", further expounds on the concept of social distance where he conceived the idea of the "stranger" who according to him represents a double-edged scenario in which an individual moves out of one group to seek for acceptance in another. The stranger though living and participating in all the group's activities, he still remains distant to the other "native" members of the group.

However, it is (Park, 1924); (a student of Simmel) who is credited with giving prominence to social distance as a sociological concept who borrowing from Simmel's "Sociologie", introduced it into the American Sociological thought. Park, pointed out that the concept of social distance is the degree of sympathetic understanding that is experienced basically by every other person concerning other people who come into his/her field of social relations. It is generally the grades and degrees of understanding and intimacy that characterize personal and social relations. Park argues that when the degree of sympathetic understanding is great, social farness occurs and the converse is true. According to him, Social distance as a concept is rooted in social norms that differentiate individuals and groups from one another based on intrinsic characteristics such as race/ethnicity, age, sex and non-intrinsic ones such as social class, religion and nationality. According to (Park, 1924), therefore, ordinarily, the greater the social distance between individuals or groups, the less influence they have for each other. He observed that prejudice is in turn the "more or less instinctive and spontaneous disposition to maintain social distances" from other groups.

According to (Bogardus, 1925), social distance as a social construct refers to the extent of social distance that individuals perceive between themselves and other social groups. Bogardus who is famous for developing the "Bogardus social distance scale." which is a measure of the affective distance between individuals or groups argued that human relations rotate around the two key tenets of sympathy and affectivity. As such, (Bogardus, 1941), notes that "where there is little sympathetic understanding, social farness exists. Where sympathetic under-standing is great, nearness exists." This type of social distance is typically subjective and it relies heavily on the actors' perceptions of the relationship.

There is also a social distance that emanates in a social relation when two individuals or groups make an objective and realistic evaluation of each other's traits and other perceivable characteristics which ultimately determine the kind of attitudes they project towards each other. This type of social distance completely overlooks philosophical questions around individuals and it rests upon a mutually acceptable set of social norms that regulate human social relations. This is what is usually referred to as the normative social distance. In this regard, a normative social distance system can be inferred as a set of collectively recognized norms about membership status in a group. These norms provide a basis for social categorization and differentiation of members of different social groups and determine the kind of relations which they enter into with others. Social norms such as those around reciprocity, justice, fairness, etc. are important in determining social relations and consequently social distance. Therefore, social distance is seen as a product of a set of welldefined group norms that hold the members together if the norms are in tandem with members' expectations but which are likely to push the members apart if there is a discrepancy between members' feelings and the normative dictates. As (Kadushin, 1962), observes social distance can be looked at "an objectively observable quantity which varies from one social structure to another,' and about which there exist "consciously expressed norms.",

Social distance as a social construction has also been conceptualized based on how frequently two social groups interact with each other. This level of social distance usually referred to as the interactive social distance is not built around any societal normative expectations but rather on the frequency and intensity of interactions between two groups. Consequently, the more the members of the two groups interact, the closer they are socially. As (Kadushin, 1962), observes interactive social distance is "the degree of actual 
interaction and need not match the normative prescriptions"'. Recent commentators on this type of social distance such as Granovetter (1973), have brought in the Network theory to show how the frequency of interaction between two parties is used as a measure of the "strength" of the socialities between them. He concludes that the frequency and length of interaction are used as two major criteria for deciding about the weakness or strength of a socialities.

The last dimension of social distance is what has been referred to as the cultural and habitual distance. This conception of social distances owes its intellectual basis to (Tarde, 1962), who proposed that the distance between two groups especially two social classes can be expressed by the degree of imitation that exists between them. Szalay and May (1983), also followed this path arguing that social distance between two groups rests upon the overall result of imitative processes, which is best exemplified by cultural similarities or to what some scholars call "psycho-cultural distance" between two groups. Pierre Bourdieu is one of the most prominent contemporary scholars of this school of thought and he proposed that social groups and classes can be mapped on a multidimensional "social space" based on the types and volume of "capital" they possess. Bourdieu posits that individual actors occupy multiple places within multiple 'relatively autonomous' fields that together constitute the social space (Bourdieu, 1990).

Understanding the sociological meaning of social distance is important in order to juxtapose it with its current usage in medical literature. The question that pops up therefore, is, whether early sociologists conceived of the concept of social distance as an abstract notion only denoting social relations between individuals and/or groups or whether it could be used to define actual physical space between individuals and groups in a continuum. While it might appear that sociologically, social distance may represent a theoretical basis for studying human interactions, it still offers certain notions that could be critical in applying it medically. This is important because even when applied in medical settings, social distancing entails a social action which can only be realized effectively if certain social constraints are eliminated and more often than not, this particular action is accompanied by a raft of negative social impacts.

The Merriam Webster Dictionary defines social distancing as the " medical practice of maintaining a greater than usual physical distance (such as six feet or more) from other people or of avoiding direct contact with people or objects in public places during the outbreak of a contagious disease to minimize exposure and reduce the transmission of infection (Merriam Webster Dictionary). The (WHO, 2009), described social distancing as "keeping at least an arm's length distance from others, [and] minimizing gatherings". It is combined with good respiratory hygiene and hand washing and is considered the most feasible way to reduce or delay a pandemic (WHO, 2009). The Centers for Disease Control and Prevention describes social distancing as staying away from mass gatherings and keeping a distance of 6 feet or $2 \mathrm{~m}$ - about one body length - away from other people (CDC, 2019). Most countries including Kenya have adopted social distancing as one of the very key mitigation strategies against the spread of Covid-19.

\section{Theoretical Framework}

This study can best be approached by using the protection motivation theory which was advanced by (Rogers, 1975), to explain the motivations for individuals to act in ways geared towards selfprotection in the face of a perceived health threat. This theory posits that human beings will more often than not engage in protective behavior(s) that ultimately minimizes the impact(s) from perceived threats. The Protection Motivation Theory (PMT) tries to explain how individuals make decisions and take actions especially when they perceive their health to be under jeopardy (Rogers, 1975). For instance, how would one react if they believed that their health is at risk because of obesity?

PMT argues that individuals will usually make a decision on whether to engage in a health-related behavior(s) through two processes; threat and coping appraisals. The former is related with level of threat as perceived by an individual. In this process an individual actor will replay the various predisposing factors to the threat and appropriately choose behavior(s) that may reduce harm. The twin concepts of perceived vulnerability and perceived severity are very instrumental to an individual's decision making process under this appraisal. Perceived vulnerability is that belief that he/she is susceptible to a disease that is potentially a health threat. Perceived severity, on the other hand, is that feeling in an individual that the health threat will have devastating consequences. The amount of fear generated by the two set of situations determine how individuals react to any perceived health threat.

Coping appraisal deals with how an individual makes an evaluation of the different factors that may ultimately push him/her to pursue a response which is preventive. This appraisal works on three sets of beliefs; response efficacy, the belief that engaging in a certain behavior is desirable for lessening the threat; self-efficacy, the belief that one has the requisite capabilities to engage in the desired behavior and lastly the perceived-response costs that deals with the costs that accrues from engaging in a specific behavior. 
PMT isn't really difficult to apply in explaining individuals' propensity to practice social distancing in the face of Covid-19. Individuals will most likely engage in the practice if they believe that they are sufficiently susceptible to the virus and that contracting it will potentially prove harmful to their health. They will also engage in the behavior if they are convinced that it will reduce the threat of infection; that they have the capabilities of engaging in the behavior and lastly if the disadvantages of engaging in the behavior outweigh the disadvantages. Therefore, for this study, the rate of adoption of social of social distancing as Covid-19 mitigation practice represents the threat appraisal which signifies a call to action based on the perceived threat; the barriers to adoption represents the capacity to engage in the practice and the social implications the opportunity cost of engaging in the behavior.

\section{Methodology}

This part of the paper lays out the methodology which was used for the study regarding research design, Sampling, Data collection and data handling and analysis.

\section{Research Design}

The study employed a descriptive study design that is loosely defined as a type of research design that attempts to describe the distribution of one or more variables, without regard to any causal or other hypotheses.

\section{Sampling}

A total of 265 respondents participated in the study. These individuals were conveniently selected from different email databases and WhatsApp groups. Table 1 gives a breakdown of the different sources from which the sample for the study was drawn.

\section{Data Collection Techniques and Tools}

A review of available literature on Covid-19 was undertaken (its history, clinical manifestations, mitigation measures and the global trends on infection and mortality). Also, secondary data on social distance as both a sociological and medical concept was collected. A triangulation of both quantitative and qualitative approaches was used to collect primary data on themes such as its meaning, adoption rates, the real or perceived barriers to its effective adoption and the social implications for those practicing it using a semi-structured questionnaire that was sent to potential respondents.

Table 1: Sample size

\begin{tabular}{lccc}
\hline Sample source & $\begin{array}{l}\text { Database } \\
\text { size }\end{array}$ & $\begin{array}{l}\text { Sample drawn }(10 \% \\
\text { of the sample) }\end{array}$ & $\begin{array}{l}\text { Total } \\
\text { sample }\end{array}$ \\
\hline Email database (Hotmail) & 675 & 75 & 75 \\
Email database (Gmail) & 400 & 40 & 40 \\
WhatsApp & 1550 & 150 & 150 \\
Total & 2625 & 265 & 265 \\
\hline
\end{tabular}

\section{Data Analysis and Handling}

This study yielded more qualitative than quantitative data. The quantitative data was first coded and input into SPPS version 26 to generate simple descriptive statistics such as frequencies and percentages. Qualitative data was analyzed using NVivo to produce thematic, narrative and content analysis. Since this study didn't intend to come up with universal generalizations of its findings, more emphasis was put into generating indepth meanings and sensitivity to context.

\section{Findings and Discussion}

This section discusses the key findings from the study.

\section{Sample Characteristics}

\section{Sex of Respondents}

As shown in Fig. 1, out of the 265 respondents, 150 (57\%) were women while $115(43 \%)$ were men.

\section{Level of Education of Respondents}

$52(20 \%)$ of the respondents had secondary school education, 47 (18\%) had post-secondary (diploma), 40 (15\%) were continuing university students, 75 (28\%) had a first degree, $45(17 \%)$ had Masters Degrees while 6 (2\%) had PhDs as shown by Fig. 2.

\section{Respondents' Distribution by County}

In terms of geographical distribution of the respondents, Nairobi county had 116 (43.77\%), Mombasa 15 (5.66\%), Tharaka Nithi 30 (11.32\%), Kajiado 24 (9.05\%), Machakos 18 (6.80\%), Makueni 14 (5.28\%), Embu (3.01\%)), Nakuru 7 (2.64\%), Kisumu 8 (3.01\%), Migori $1(0.38 \%)$, Kirinyaga $1(0.38 \%)$ Meru 6 $(2.26 \%)$, Nyeri 5 (1.89\%), Kakamega 3 (1.13\%), Kitui 7 (2.64) and Mwingi 2 (075\%) (Fig. 3).

\section{Occupation of Respondents}

Regarding respondents' occupations 82 (31\%) were unemployed; 47 (18\%) students; 45 (17\%) University lecturers; 17 (6\%) salespersons; 55 (21\%) businesspersons; $2(0.8 \%)$ medical doctors; 8 (3\%) Accountants; 2 (0.8\%); Social Workers and 7 (2\%) high school teachers (Fig. 4).

\section{Number of People in a Single Dwelling}

The range of residents per single dwelling was between 1 and 15 individuals with a mean of 4 .

\section{Respondents Understanding of Social Distancing as a Coronavirus Mitigation Strategy}

$100 \%$ of the respondents reported that they were aware of the concept of social distancing in the context 
of the Coronavirus pandemic. $85 \%$ of those surveyed Said that social distancing was a guideline which had been given by health officials which entailed keeping a distance of between 1 to $1.5 \mathrm{~m}$ from one individual to another to minimize the spread of the Coronavirus. $15 \%$ of the respondents put the distance at 1 meter. However, the majority of the respondents were aware that social distancing had been recommended by the Ministry of Health and the World Health Organization as a strategy for containing the spread of the Coronavirus. Regardless of the level of education, $100 \%$ of the respondents were aware that social distancing entails keeping a distance of $1 \mathrm{~m}$ and above between one person and another to fight the spread of Coronavirus. However, a significant number of respondents $(85 \%)$ admitted that they had no prior knowledge of the concept of social distancing before the outbreak of the Coronavirus. They also admitted that they had previously never been in a situation which called for social distancing. $15 \%$ of the respondents, however, acknowledged to having prior knowledge of the phenomenon even before the onset of the coronavirus pandemic.

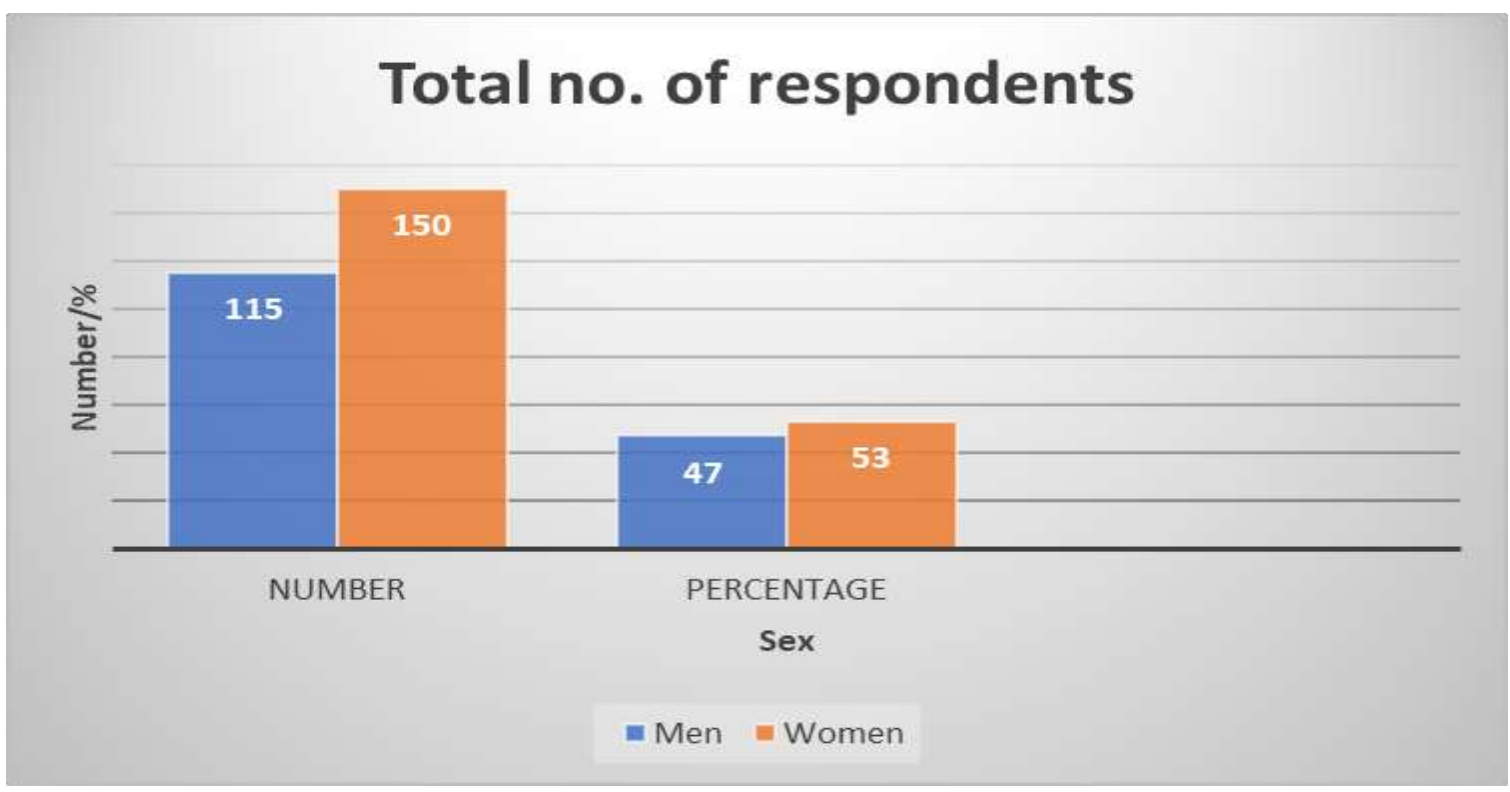

Fig. 1: Total number of Respondents; Age of respondents: The age range of the respondents was between 18 and 65 years with a mean of 30 years

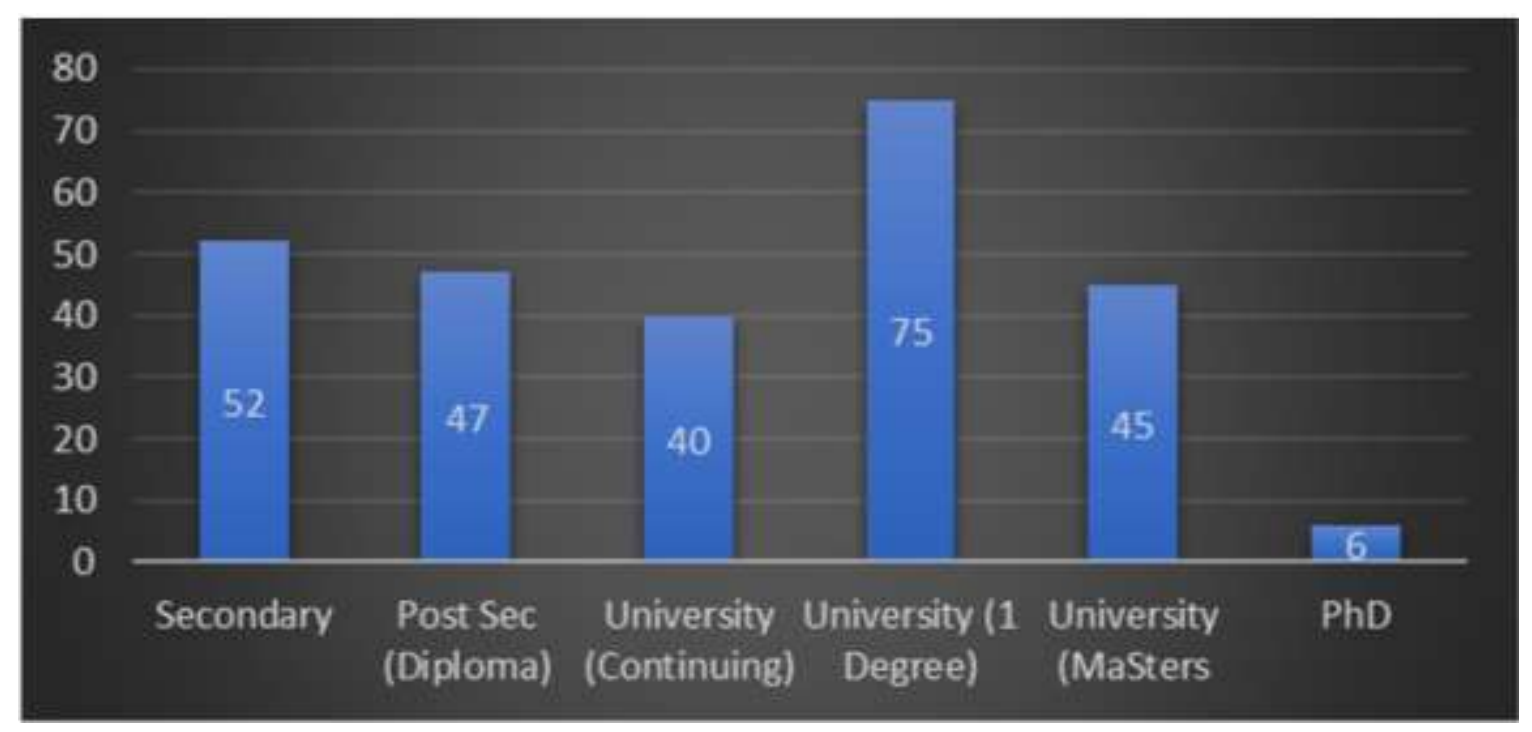

Fig. 2: Respondents' level of education 


\section{No of Respondents by County}

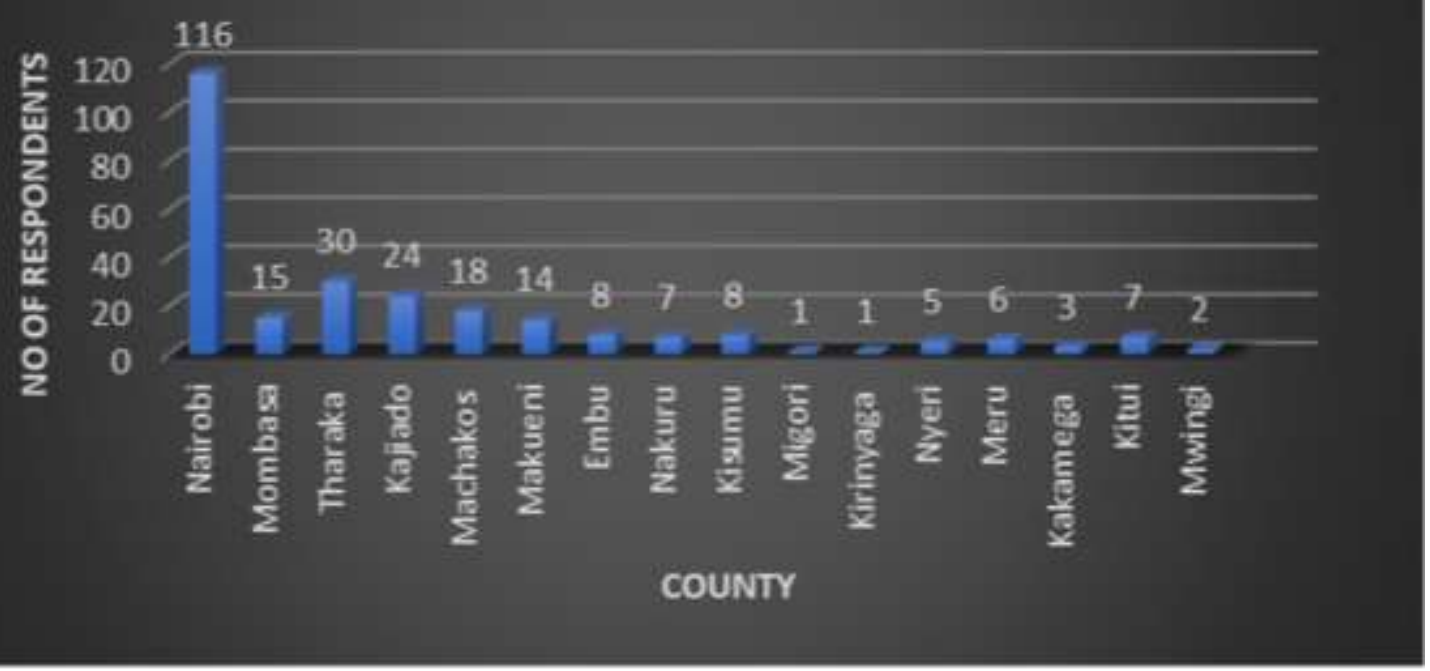

Fig. 3: Distribution of respondents by county

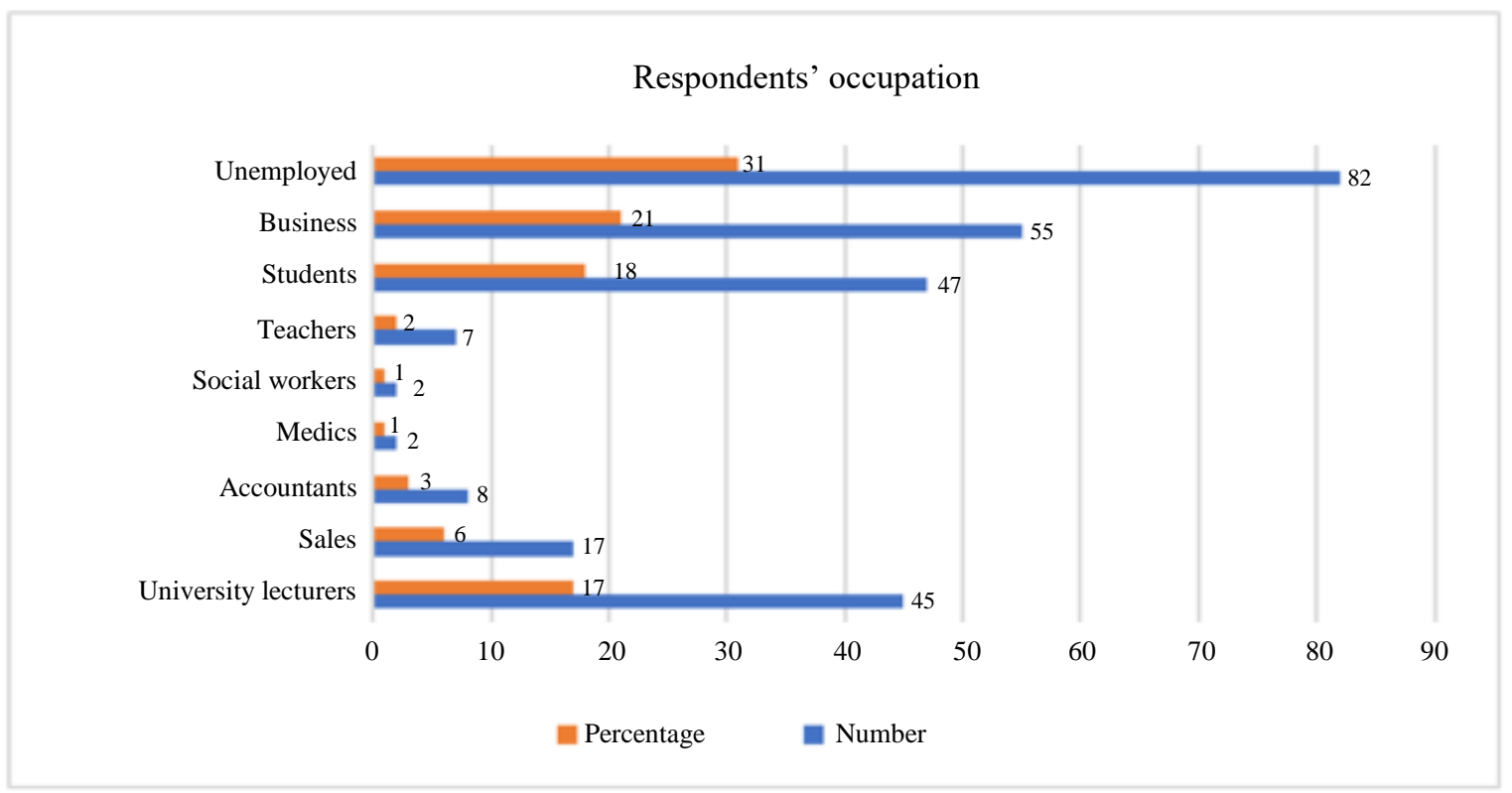

Fig. 4: Respondents occupation

Respondents Views on the Efficacy of Social Distancing as a Strategy for Minimizing the Spread of Coronavirus

All the participants $(100 \%)$ thought that social distancing was an effective strategy for mitigating the spread of the pandemic. There are no disparities in this observation arising from an individual's socio-economic characteristics such as the level of education, occupation, age and sex. The general feeling among the majority of respondents was that coming into contact with an infected person would increase their chances of infection. Therefore, social distancing was the most efficacious strategy for controlling the spread of the virus. One respondent in the qualitative part of the response had this to say:

"This virus doesn't move; it is us individuals who move it. So, the best way of minimizing its spread is by people keeping some safe distance between each other" 


\section{Adoption of Social Distancing as a Mitigation Strategy for Spread of Coronavirus}

A significant proportion of the respondents (98\%) reported that they were observing the WHO guidelines of social distancing as a strategy for containing the spread of Coronavirus. This was regardless of respondents' socio-economic characteristics such as sex, level of education, occupation and age. Only a paltry $(2 \%)$ of the respondents reported they were not observing the WHO guidelines on Social distancing. Those observing the WHO guidelines identified different social environments in which they were exercising social distancing. All respondents $(100 \%)$ reported that they were exercising social distancing at home. $95 \%$ of the women said that they were observing social distancing in the Supermarkets and grocery outlets as opposed to 5\% for men. A smaller number of respondents $(5 \%)$ also indicated that they were observing social distancing at Automated Teller Machines and in banking halls. The majority of the respondents who pointed out that they were observing social distancing in ATMs and at banking halls were business people. However, it should be noted that the small percentage reporting this could be explained by the fact that most people have switched to other electronic money platforms such as Mobile money transfers and electronic banking to carry out their transactions. $85 \%$ of the respondents also reported observing social distancing when walking. For those respondents who were working from the office, all of them $(100 \%)$ said they were observing social distancing at their places of work. A further $75 \%$ of the respondents indicated that they were observing social distancing in public transport. A paltry 1 and $2 \%$ of the respondents reported that they were also observing social distancing when visiting friends and in health facilities respectively, Therefore, it was observed that an individual's socio-economic characteristics such as sex and occupation have a big bearing on the social environments in which individuals exercise Social distancing as a mitigation strategy for the spread of Coronavirus.

The $2 \%$ of the respondents who reported that they were not actively observing social distancing protocols gave various explanations for it. This scenario was more acute among respondents in farflung counties and ones which were far away from the epicenters of the virus such as Migori, Tharaka Nithi, Meru, Kakamega, Meru and Nyeri. Such individuals felt that the virus was too far away from their localities to warrant such severe measures. One respondent put it this way:

"Occasionally, rather unconsciously I find myself in contravention while interacting with friends and family, sometimes on the belief that the virus is still a distance from my residing county (MIGORI); this informs my recklessness practice by me - I guess"

\section{Potential Barriers to Effective Adoption of Social Distancing as a Mitigation Strategy for the Spread of Coronavirus}

Despite all the respondents readily agreeing that Social distancing remains one of the most potent strategies for mitigating the spread of Coronavirus, there were certain barriers to its successful implementation. $85 \%$ of the respondents stated that poverty remained the greatest obstacle to the successful adoption of social distancing as a strategy for stemming the spread of the Coronavirus. They pointed out in a country where a great majority of individuals especially in the urban centers eke their living from informal businesses, it would be impossible to put in place a successful Social distancing strategy. This was best captured by one of the responses to the question in which a respondent asserted:

\begin{abstract}
"Implementing social distancing in this country is almost impossible. There are so many people out there searching for a livelihood. There are so many people in the streets, in the open-air markets, in public transport. It is almost impossible to maintain social distancing under the circumstances".
\end{abstract}

$80 \%$ of the respondents singled out ignorance as a potential barrier to instituting a successful social distancing strategy. Some respondents stated that ignorance was manifested among the Kenyan population by the way people just went about their normal lives without exercising social distancing in many instances. One participant had this to say:

"Some people are oblivious to the social distancing phenomenon so as you try to keep distance it is like they're following you."

Another $45 \%$ of the respondents cited recklessness among Kenyans as a barrier to the adoption of a successful social distancing strategy. Of particular concern among these respondents was the observation that even though Kenyans were aware of the consequences of overcrowding, they were doing very little to avoid it as evidenced in various social places such as markets, public transport, supermarkets and in places of worship. As one respondent observed:

"Kenyans are generally carefree and careless people. They tend to ignore any warnings 
about imminent danger. We have witnessed situations in this country where people are warned against certain issues but they still ignore the cautions"

$50 \%$ of the respondents pointed out that culture was also an impediment to successful social distancing. They opined that Kenyans specifically and Africans generally don't respect personal space and they are most likely to end up keeping close to each other regardless of the health and other implications. One respondent captured this by stating:

"The concept of social distancing is very alien to the African culture. We Africans express our feelings through close social contact and that is why in our culture handshaking is a very important gesture. People feel offended if you don't offer them a handshake."

Lastly, $38 \%$ of the respondents singled out lack adequate physical space as a barrier to successful social distancing. They pointed out this was more apparent in individuals living in congested dwellings such as in slums and other informal settlements. One respondent had to this to say:

"It is almost impossible to expect poor people living in slums like Kibera or Mathare to observe social distancing in cases where you find around 5 people living in one room which serves as the living, cooking and sleeping room."

The respondents surveyed during the study pointed out that all these barriers (either singularly or in combination) could pose a serious threat to the successful observation of social distancing as a mitigation strategy for the spread of Coronavirus in the country (Fig. 5).

\section{Social Implications of Social Distancing as a Corona Spread Mitigation Strategy}

$98 \%$ of the respondents reported that observing social distancing had led to the collapse of social bonds leading to a situation whereby individuals felt alienated. They were of the view that this could cause serious psychological distress to individuals. It was also observed that social distancing had imposed very severe strains on family socialization and intimacy. This was aptly captured by one of the respondents who said:

"This social distancing has completely disrupted our social lives. When in the house everyone is keeping their safe distance doing their things. You can't even come close to your kids, it is terrible."

A further $83 \%$ of the respondents felt that social distancing was adulterating the long-held and cherished African cultural customs and values of sticking together at all times. They argued that it would be very hard to explain to people especially in the rural areas why they could not shake hands and attend cultural ceremonies.

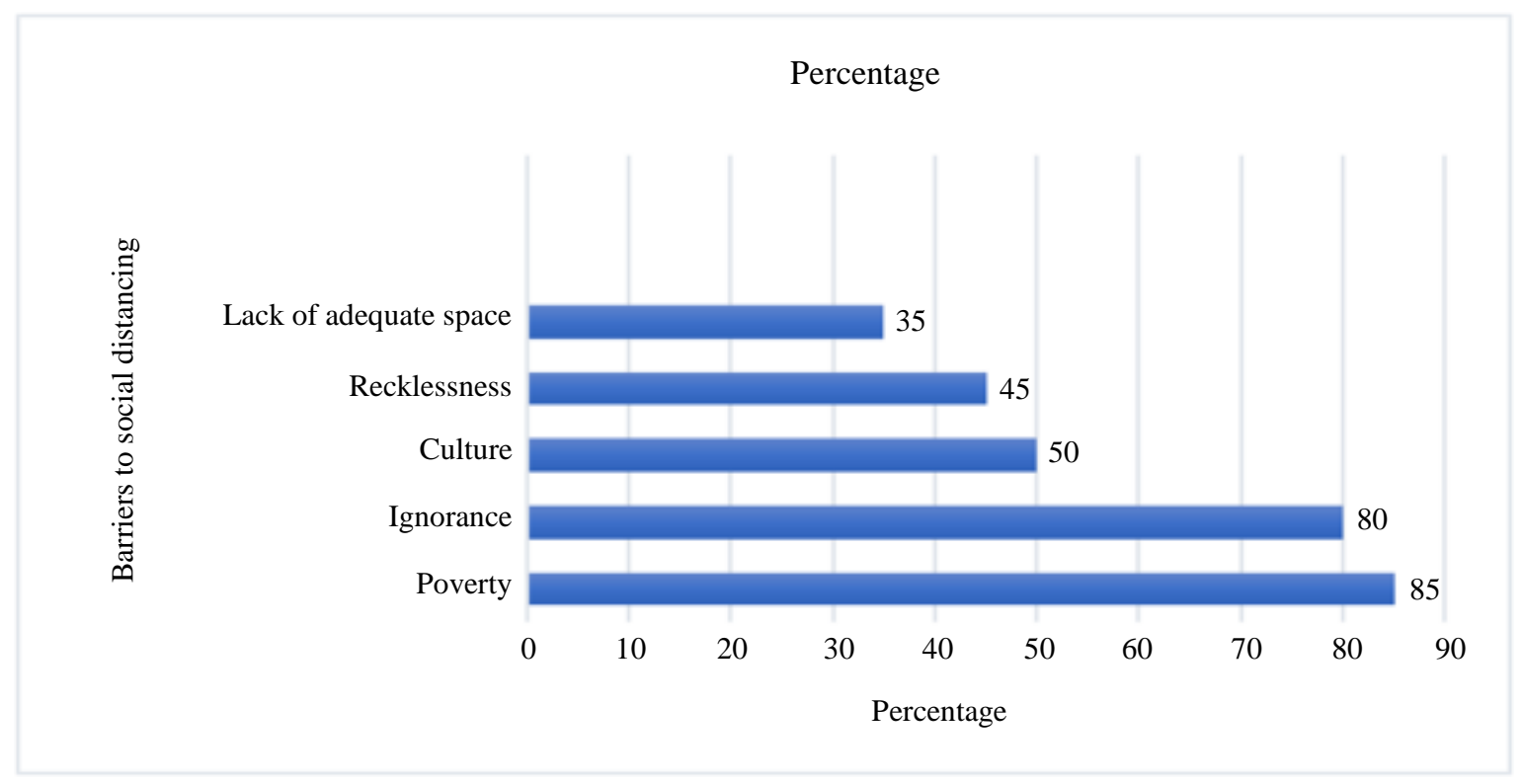

Fig. 5: Barriers to effective social distancing 
There were those who, however, felt that social distancing had positive social implications. $15 \%$ of the respondents stated that social distancing had created a new thinking around social interactions and that Kenyans were increasingly accepting the fact people could still socialize but from a distance. They pointed out this practice had demystified the long-held notion that socialization was only possible if people are in close contact. This assertion was more pronounced among those individuals with higher levels of education. One respondent has this to say:

\section{"We have been programmed to think that only meaningful social interaction is only possible when individuals come close together. Since the onset of $l$ social distancing as a measure for containing the spread of the coronavirus, individuals are increasingly appreciating the fact that they can still interact regardless of physical distance."}

Another 5\% of the respondents pointed out that social distancing would have very positive implications in the long run especially in the reduction of other contagious medical conditions such as Tuberculosis, skin diseases and Sexually Transmitted Illnesses.

\section{Conclusion and Recommendations}

Though the sample used for this survey may not be representative of the Kenyan population, this study still offers very vital insights around the concept of social distancing in the context of the Coronavirus pandemic. One of the most encouraging insights is that a big proportion of the population is aware of the concept as a critical intervention for stemming the spread of the virus. Secondly, a great majority of individuals are practicing social distancing as a mitigation strategy for the spread of the Coronavirus. Thirdly, even though individuals are willing to exercise social distancing as a precaution against the spread of the virus, other intervening variables may curtail the effective adoption of this intervention. Such variables may include poverty, peoples' attitudes and beliefs, ignorance. Fourthly, in as much as individuals are willing to exercise social distancing as a mitigation strategy, it comes along with negative social implications.

\section{Given the Above Observations, this Paper Recommends the Following}

The government should still scale up sensitization programs around the concept of social distancing to mitigate the spread of the Coronavirus and any other similar pandemic which may occur in the future. The import of this is to let individuals social distancing isn't a punitive measure by the state but rather a very beneficial intervention for stemming the spread of the Virus.
The government should in the future put in place concrete measures to address the plight of the vulnerable members of society especially those who cannot practice social distancing due to economic realities. Such measures may include social protection programs such as cash and essential services provided to the vulnerable members of society.

\section{Acknowledgment}

The author is immensely grateful to all the respondents who participated in this study. I cannot thank each one of you in person but the information you provided was invaluable to the study.

\section{Ethics}

The author observed all the requisite research protocols including the right to informed consent; confidentiality and integrity in data collection and analysis.

\section{References}

Bogardus, E. S. (1925). Measuring social distance. Journal of applied sociology, 9, 299-308. https://ci.nii.ac.jp/naid/10018690990/

Bogardus, E. S. (1941). Sociology. New York: Macmillan.

Bourdieu, P. (1990). Social space and symbolic power. In In Other Words, Polity Press. http://citeseerx.ist.psu.edu/viewdoc/summary?doi=1 0.1.1.587.5347

CDC. (2019). https://www.cdc.gov/coronavirus/2019ncov/about/prevention-treatment.html

Dahab, M., Van Zandvoort, K., Flasche, S., Warsame, A., Ratnayake, R., Favas, C., ... \& Checchi, F. (2020). COVID-19 control in low-income settings and displaced populations: what can realistically be done? Conflict and Health, 14(1), 1-6. https://www.lshtm.ac.uk/newsevents/news/2020/cov id-19-control

Granovetter, M. S. (1973). The strength of weak ties. American journal of sociology, 78(6), 1360-1380. https://doi.org/10.1086/225469

Kadushin, C. (1962). Social distance between client and professional. American Journal of Sociology, 67(5), 517-531. https://doi.org/10.1086/223189

Lupia, T., Scabini, S., Mornese Pinna, S., Di Perri, G., De Rosa, F. G., \& Corcione, S. (2019). novel coronavirus (2019-nCoV) outbreak: a new challenge. J Glob Antimicrob Resist., 21, 22-7. https://doi.org/10.1016/j.jgar.2020.02.021

NIH. (2020). NIH officials discuss novel coronavirus that recently emerged in China. https://www.nih.gov/news-events/news-releases/nihofficials-discuss-novel-coronavirus-recentlyemerged-china 
Park, R. E. (1924). The concept of social distance: As applied to the study of racial relations. Journal of applied sociology, $8, \quad 339-334$. https://ci.nii.ac.jp/naid/10030116428/

Park, R. E., \& Burgess, E. (1921). Introduction to the science of sociology. Chicago: University of Chicago Press.

Rogers, R. W. (1975). A protection motivation theory of fear appeals and attitude change1. The journal of psychology,

91(1),

93-114. https://doi.org/10.1080/00223980.1975.9915803

Simmel, G. (1906). The sociology of secrecy and of secret societies. American journal of sociology, 11(4),

441-498. https://www.journals.uchicago.edu/doi/abs/10.1086/ 211418

Szalay, L. B., \& Maday, B. C. (1983). Implicit culture and psychocultural distance. American Anthropologist, $\quad$ 85(1), 110-118. https://www.jstor.org/stable/676036?seq=1

Tarde, G. (1962). The Laws of Imitation (trans: Howell, R.). Gloucester, MA: Peter Smith.

Wang, N., Shi, X., Jiang, L., Zhang, S., Wang, D., Tong, P., ... \& Wang, X. (2013). Structure of MERS-CoV spike receptor-binding domain complexed with human receptor DPP4. Cell research, 23(8), 986-993. https://doi.org/10.1038/cr.2013.92

WHO. (2009). Pandemic influenza prevention and mitigation in low resource communities.

WHO. (2020a). Coronavirus disease 2019 (COVID-19): situation report, 60 .

https://www.who.int/emergencies/diseases/novelcoronavirus-2019/advice-for-public?
WHO. (2020b) Novel Coronavirus-China. https://www.who.int/csr/don/12-january-2020novel-coronavirus-china/en/?

WHO. (2021). WHO Coronavirus Disease (Covid-19) Dashboard. https://covid19.who.int/

WMHC. (2020). Wuhan Municipal Health and Health Commission's Briefing on the Current pneumonia Epidemic situation in Our City. http://wjw.wuhan.gov.cn/front/web/showDetail/201 9123108989

Yang, Y., Peng, F., Wang, R., Guan, K., Jiang, T., Xu, G., ... \& Chang, C. (2020). The deadly coronaviruses: The 2003 SARS pandemic and the 2020 novel coronavirus epidemic in China. Journal of Autoimmunity, 109, 102434. https://doi.org/10.1016/j.jaut.2020.102434

Zhong, N. S., Zheng, B. J., Li, Y. M., Poon, L. L. M., Xie, Z. H., Chan, K. H., ... \& Guan, Y. (2003). Epidemiology and cause of severe acute respiratory syndrome (SARS) in Guangdong, People's Republic of China, in February, 2003. The Lancet, 362(9393), 1353-1358. https://doi.org/10.1016/S01406736(03)14630-2

Zhu, N., Zhang, D., Wang, W., Li, X., Yang, B., Song, J., ... \& Tan, W. (2020). A novel coronavirus from patients with pneumonia in China, 2019. New England journal of medicine. https://doi.org/10.1056/NEJMoa2001017 